\title{
Antenatal Sonographic Diagnosis of a Case of Alobar Holoprosencephaly
}

\author{
*S Rima ${ }^{1}$, M T Aziz 2 , R Amin 3 , M A Abedin ${ }^{4}$
}

\begin{abstract}
Holoprosencephaly, a disorder resulting from failure of cleavage or incomplete differentiation of the forebrain structures at various levels or to various degrees, is related to hereditary factors, chromosomal anomalies, cytogenetic abnormalities, and environmental teratogenic factors. This anomaly is resulted from the failure of diverticulation and cleavage of primitive prosencephalon during weeks 4-8 of gestation. In this study, we described a case of HPE in a neonate with gestational age of 35 weeks.
\end{abstract}

Key Words: Alobar holoprosencephaly, Pregnancy, Antenatal Ultrasonography

\section{Introduction}

In 1963, Demyer and Zeman proposed the term holoprosencephaly which is a disorder resulting from failure of septation, cleavage, or differentiation of the midline forebrain structures at various levels or to various degrees. Sonography is an excellent non-invasive tool for pre-natal diagnosis of holoprosencephaly. This case report describes a case of alobar holoprosencephaly diagnosed prenatally with ultrasound and highlights the importance of high-resolution real time imaging.

\section{Case Report}

A 30-year-old gravida 2 and para 1 female referred at 35 th week gestation, for routine antenatal ultrasonography. There were no symptoms or signs suggestive of any clinical condition. The patient had no history of diabetes mellitus, hypertension with the previous child being born at term with no congenital anomaly. General physical examination was unremarkable. The uterus was gravid. There was singleton fetus in cephalic presentation. The fetal heart sound was 145 beats per minute. Antenatal ultrasonographic diagnosis was performed, and the infant was presented with lateral ventricles are grossly enlarged. There is complete absence of forebrain division resulting in a monoventricle and cortical tissue is almost absent.

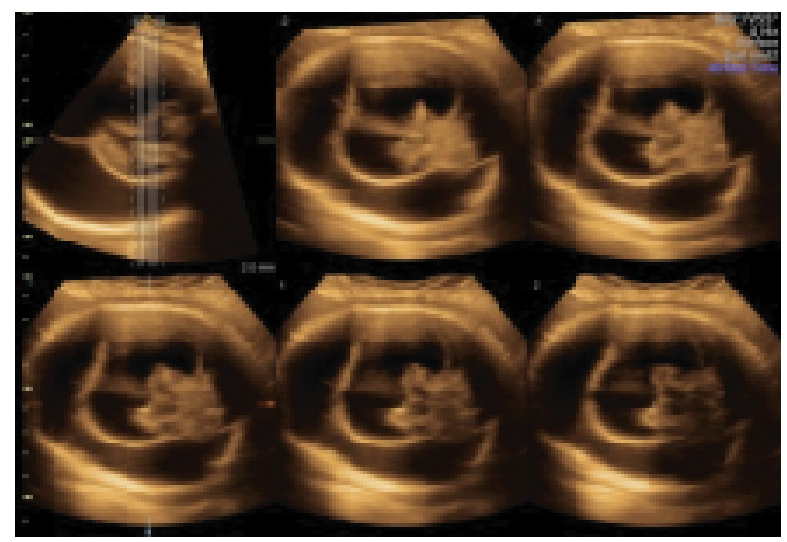

Fig: Mono-ventricle and cortical tissue is almost absent. Both thalami are fused and absent corpus callosum, inter-hemispheric fissure cavum septum pellucidum $\& 3^{\text {rd }}$ ventricle.

Both thalami are fused and corpus callosum, interhemispheric fissure, cavum septum pellucidum \& 3 rd ventricle is absent. Cerebellum is markedly hypoplastic.

\footnotetext{
${ }^{1}$ Dr. Shamim Rima, Assistant Professor, Dept. of Radiology \& Imaging, Anwer Khan Modern Medical College

${ }^{2}$ Dr. Md. Tarik Aziz, Assistant Registrar, Dept. of Surgery, Anwer Khan Modern Medical College Hospital

${ }^{3}$ Dr. Rumana Amin, Medical Officer, Dept. of Paediatrics, Anwer Khan Modern Medical College Hospital

${ }^{4}$ Dr. M. Afsar Abedin, Lecturer, Dept. of Anatomy, Anwer Khan Modern Medical College

*Corresponding author
}

Date of submission: 05.05.2017, Date of acceptance: 10.07.2017

AKMMC J 2018; 9(1) : 68-70 


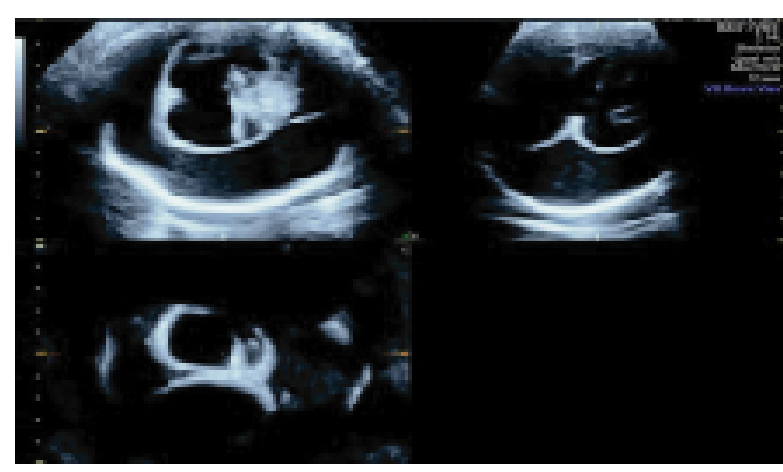

Fig: Markedly hypoplastic cerebellum

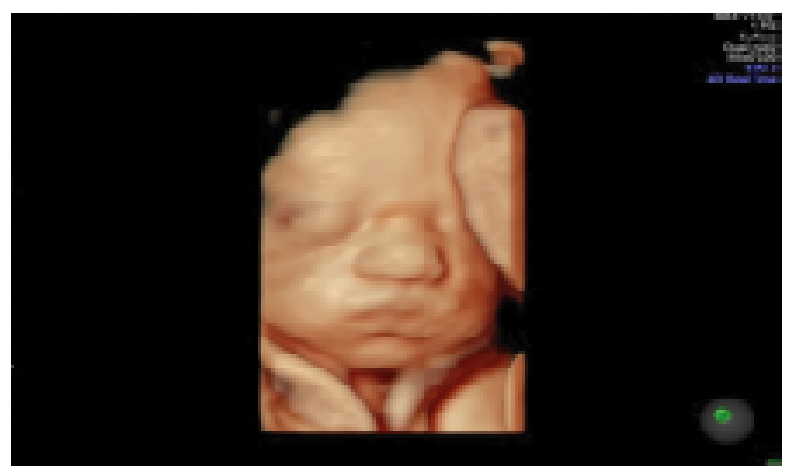

Fig: Normal facial structures

Based on the ante-natal sonographic findings a diagnosis of alobar holo-prosencephaly was made. The couple requested for the termination of pregnancy because of the poor fetal prognosis. This was performed by administration of vaginal prostaglandin (misoprostol). Postmortem clinical examination revealed a female newborn with normal body structure. The couple declined consent for autopsy.

\section{Discussion}

Holoprosencephaly (HPE), a disorder which results from a failure of cleavage or the incomplete differentiation of the forebrain structures at a various levels or to a various degree. The incidence of holoprosencephaly is approximately $1-1.4$ per 10,000 live births but as the incidence of spontaneous abortions is high, the actual incidence may be quite high. Both environmental factors and genetics are suspected in its etiology and approximately $30 \%$ of the cases are associated with chromosomal defects mostly trisomy 13 and 18 . However most of the cases have a normal karyotype. HPE is classified into different types, including alobar, semi-lobar, lobar and middle interhemispheric (middle interhemispheric possible that this is not a variant of HPE at all, but is currently classified as such). Alobar holoprosencephaly is the most severe defect in which there is no cleavage of the forebrain (prosencephalon) which leads to single ventricular cavity and this lead to defects in the development of brain structures and functions and also in the development of the face. In semi-lobar HPE partial posterior separation of the hemispheres and the absence of optic tracts and olfactory bulbs are observed. The least severe structural defect is lobar HPE with particularly separated hemispheres and fusion of the lateral ventricles. Syntelencephaly, or middle interhemispheric variant of holoprose-ncephaly (MIHV), in which the posterior frontal lobe and the parietal lobe are not properly separated, but the rostrobasal forebrain properly separates. The various holoprosencephalic abnormalities of the face include cyclopia, proboscis, ethmocephalus, cebocephaly, premaxilla agenesis, median cleft palate/lip, and other less severe facial dysmorphism. The etiology of holoprosencephaly indicates interactions with both genetic and environmental factors, including chromosomal anomalies, gene rearrangements, mendelian mutations, and teratogens and several risk factors have been proposed, including smoking habits, alcoholism, maternal diabetes mellitus, pregnancy infections (e.g., syphilis, toxoplasmosis, rubella, herpes and cytomegalo virus) and use of medications during pregnancy (e.g., aspirin, lithium, thorazine, anticonvulsants, birth control pills and retinoic acid). Early detection by sonography offers a better and earlier diagnostic procedure than amniocentesis. The earliest gestational age at the time of diagnosis was 14 weeks. Because of the short life span and ominous outcome in all patients with alobar holoprosencephaly, genetic counseling and prenatal diagnosis by ultrasound (transabdominal or transvaginal scanning) are of great importance for early detection and allows earlier termination of the pregnancy. Infants with HPE have a variable survival rates depending on the severity of the defect. However it is common for surviving children to manifest a variety of neurological 
disorders, including cognitive and developmental delays, seizures, motor impairment and endocrinological dysfunction. According to the National Institute of Neurological Disorders and Stroke (NINDS), the majority of cases diagnosed with HPE are of the severe type, and this condition could lead to neonatal mortality and stillbirth.

\section{Conclusion}

In conclusion, patients diagnosed with HPE should receive individualized treatment despite possible complications; in general, HPE treatment is symptomatic and supportive. Prognosis of HPE depends on the severity of brain abnormalities, facial malformations and clinical complications. Severe HPE is a fatal condition in the majority of cases, as the neonate in the current study died immediately after birth.

\section{Conflict of interest: None}

\section{References}

1. DeMyer W, Zeman W, Palmer CG. The face predicts the brain: diagnostic significance of median facial anomalies for holoprosencephaly (arhinencephaly). Pediatrics 1963; 34: 256-63.

2. National Institute of Neurological Disorders and Stroke. Holoprosencephaly information page [Internet]. 2007. Available from: http://www. ninds.nih.gov/disorders/holoprosencephaly/ holoprosencephaly.htm.
3. Raam MS, Solomon BD, Muenke M. Holoprosencephaly: a guide to diagnosis and clinical management. Indian Pediatrics 2011; 48(6): 457-66.

4. National Human Genome Research Institute. Learning about holoprosencephaly [Internet]. 2012. Available from: https: // www. genome. gov/ 12512735.

5. J. P. McGahan, D. A. Nyberg and L. A. Mack, "Sono- graphy of Facial Features of Alobar and Semilobar Holo- prosencephaly," American Journal of Roentgenology 1990; 154(1): 143-148.

6. Leoncini E, Baranello G, Orioli IM, et al. Frequency of holoprosencephaly in the international clearing house Birth defects surveillance system: Searching for population variation. Birth Defects Res A Clin Mol Teratol 2008 Aug; 82(8): 585-91.

7. K. K. W. Fong, A. Toi, S. Salem et al, "Detection of Fetal Structural Abnormalities with US during Early Pregnancy," Radiographics 2004; 24(1): 157-174.

8. Traggiai C, Stanhope R. Endocrinopathies associated with midline cerebral and cranial malformations. J Pediatrics 2002; 140: 252-5. 